Ramona Miske, $\mathrm{PhD}$ *

Stefanie Hahn, PhD*

Thorsten Rosenkranz,

MD

Matthias Müller, MD

Inga M. Dettmann, PhD

Swantje Mindorf

Yvonne Denno

Stefanie Brakopp, PhD

Madeleine Scharf, PhD

Bianca Teegen, $\mathrm{PhD}$

Christian Probst, $\mathrm{PhD}$

Nico Melzer, MD

Hans-Michael Meinck, MD

Christoph Terborg, MD

Winfried Stöcker, MD

Lars Komorowski, $\mathrm{PhD}$

Correspondence to

Dr. Komorowski:

l.komorowski@euroimmun.de

Supplemental data at Neurology.org/nn

\section{Autoantibodies against glutamate receptor $\delta 2$ after allogenic stem cell transplantation} OPEN

\section{ABSTRACT}

Objective: To report on a Caucasian patient who developed steroid-responsive transverse myelitis, graft vs host disease of the gut, and anti-GluR 22 after allogenic stem cell transplantation.

Methods: Histoimmunoprecipitation (HIP) with the patient's serum and cryosections of rat and porcine cerebellum followed by mass spectrometry was used to identify the autoantigen. Correct

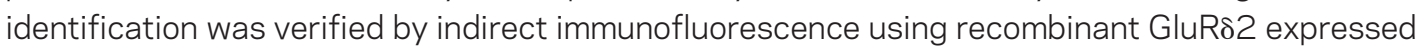
in HEK293 cells.

Results: The patient's serum produced a granular staining of the cerebellar molecular layer (immunoglobulin G1 and immunoglobulin G3; endpoint titer: 1:1,000) but did not react with other CNS tissues or 28 established recombinant neural autoantigens. HIP revealed a unique protein band at

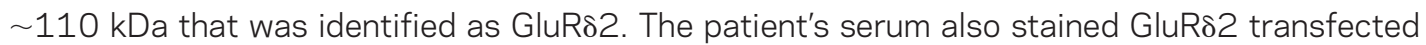
but not mock-transfected HEK293 cells. Control sera from 38 patients with multiple sclerosis, 85 patients with other neural autoantibodies, and 205 healthy blood donors were negative for

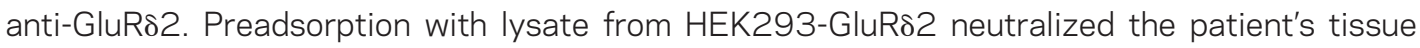
reaction whereas control lysate had no effect. In addition to anti-GluR 2 , the patient's serum contained immunoglobulin $\mathrm{G}$ autoantibodies against the pancreatic glycoprotein CUZD1, which are known to be markers of Crohn disease.

Conclusions: In the present case, the development of anti-GluR 22 was associated with transverse myelitis, which was supposedly triggered by the stem cell transplantation. Similar to encephalitis in conjunction with anti-GluR $\delta 2$ reported in a few Japanese patients, the patient's neurologic symptoms ameliorated after steroid therapy. Neurol Neuroimmunol Neuroinflamm 2016;3:e255; doi: 10.1212/NXI.0000000000000255

\section{GLOSSARY}

CASPR2 = contactin-associated protein 2; DPPX = dipeptidyl aminopeptidase-like protein; HIP = histoimmunoprecipitate; IFA = indirect immunofluorescence assay; IgG = immunoglobulin G; NMDAR = NMDA receptor; $\mathbf{N S A}=$ neuronal surface autoantibodies; RC-IFA = recombinant cell indirect immunofluorescence assay; SDS-PAGE = sodium dodecyl sulfate polyacrylamide gel electrophoresis.

Autoantibodies against neuronal surface antigens have become well-recognized biomarkers in several treatable immune-mediated CNS disorders. ${ }^{1,2}$ In general, they are associated with inflammatory damage to the CNS, and patients typically present with seizures, impairment of vision, psychosis-like symptoms, or movement disorders, or any combination, without clear-cut lead symptoms in the early stages. ${ }^{2}$

Neuronal surface autoantibodies (NSA) are directed against a wide variety of receptors or channel proteins including NMDA receptor (NMDAR), AMPA receptors 1 and $2, \gamma$-aminobutyric acid A and B receptors, leucine-rich, glioma inactivated 1 and contactin-associated protein 2 (CASPR2), glycine receptor, dipeptidyl aminopeptidase-like protein (DPPX), metabotropic

\footnotetext{
*These authors contributed equally.

From the Institute of Experimental Immunology (R.M., S.H., I.M.D., S.M., Y.D., S.B., B.T., C.P., W.S., L.K.), Euroimmun AG, Lübeck; Department of Neurology (T.R., M.M., C.T.), Asklepios Klinik St. Georg, Hamburg; Department of Neurology (N.M.), University of Münster; and Department of Neurology (H.-M.M.), University of Heidelberg, Germany.

Funding information and disclosures are provided at the end of the article. Go to Neurology.org/nn for full disclosure forms. The Article Processing Charge was paid by Euroimmun AG.

This is an open access article distributed under the terms of the Creative Commons Attribution-NonCommercial-NoDerivatives License 4.0 (CC BY-NC-ND), which permits downloading and sharing the work provided it is properly cited. The work cannot be changed in any way or used commercially.
} 
glutamate receptor 5 , and IgLON family member $5 .^{2}$ Some of them have been shown to affect surface structure and synaptic plasticity of cultured primary neurons and lead to neurologic symptoms after intrathecal application to model animals. ${ }^{3}$ Moreover, immunomodulatory treatment often not only causes NSA titers to decline but also improves the disease status. NSA are therefore generally deemed to have a direct pathogenic role.

We report on a patient who presented with severe transverse myelitis and graft vs host disease of the gut 2 years after allogenic stem cell transplantation and had developed autoantibodies against neuronal glutamate receptor $\delta 2$.

METHODS Descriptions of the patient, the controls, and healthy participants as well as the methods are provided at Neurology.org/nn.

RESULTS Case report. A 53-year-old Caucasian man had been diagnosed with myeloproliferative disease 3 years before. One year later, he received allogenic stem cell transplantation combined with thymoglobulin, busulfan, and cyclophosphamide treatment. One year before admission, he developed gastrointestinal graft vs host disease that was treated with $50 \mathrm{mg} /$ day cyclosporine. In addition, BK virus-associated cystitis and mucositis as well as a cold agglutinin disease were diagnosed and treated with acyclovir, trimethoprim/ sulfamethoxazole 1:5, and rituximab. He presented with fatigue, myoclonic jerks of the legs, tetraparesis, and incontinence. On clinical work-up, he demonstrated exaggerated deep tendon reflexes of the legs, pyramidal signs, bilateral hypesthesia and hypalgesia below $\mathrm{TH} 8$, and ataxia with unsteadiness of gait, as well as fecal and urinary incontinence.

MRI of the spinal cord revealed T2-hyperintense beaded, partially contrast enhancing lesions between $\mathrm{C} 4$ and Th8 indicative of transverse myelitis (figure 1A). Cranial MRI showed an enlarged homogenously contrast-enhancing hypophysis indicative of hypophysitis (data not shown).

Blood testing demonstrated no antibodies against neurotropic viruses (herpes simplex 1/2, Cytomegalovirus, Epstein-Barr, varicella-zoster, hepatitis B/C, lymphochoriovirus, polio, Echo) or bacteria

Figure 1 Spinal cord MRI and immunofluorescence staining of the patient's serum and controls on different tissues and recombinant cell substrates
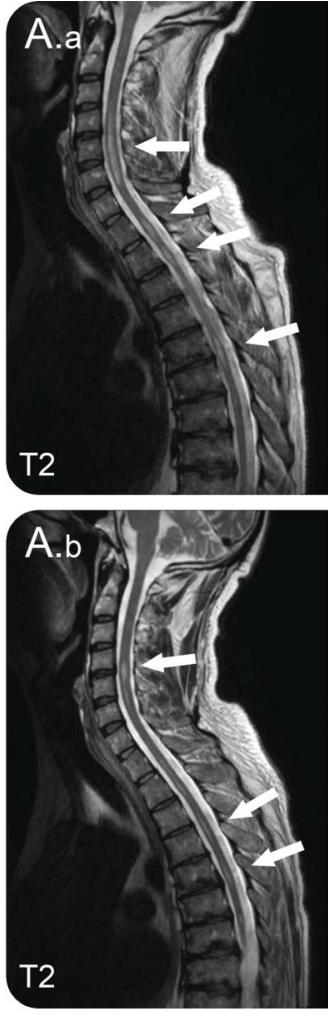
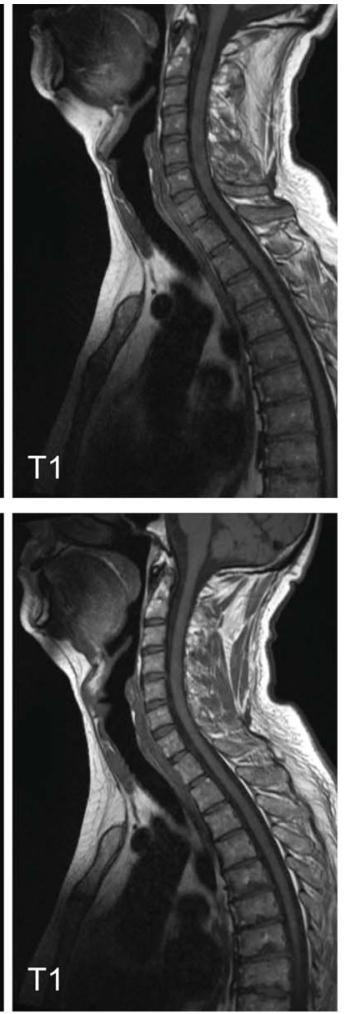
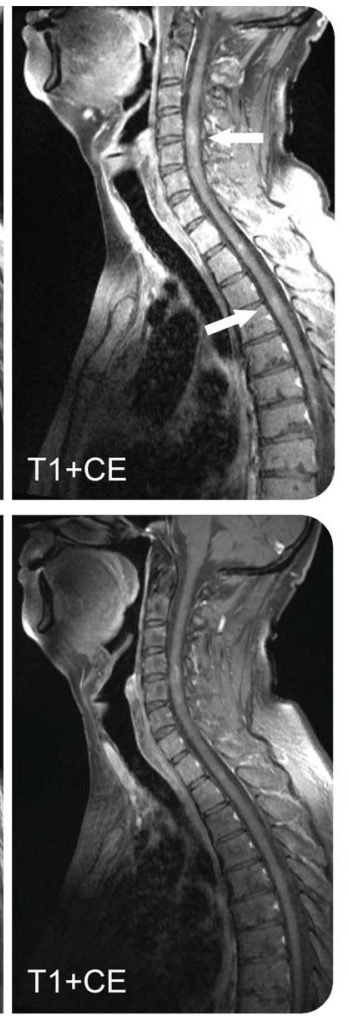
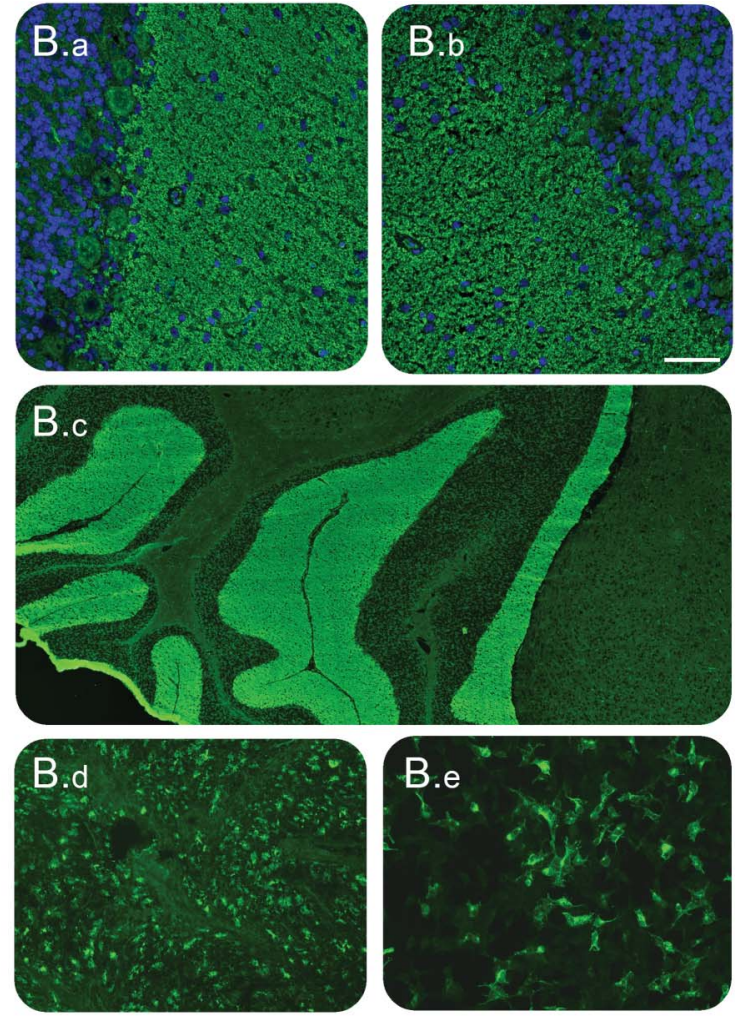

(A) MRI of the cervical spinal cord. (A.a) MRI before prednisolone treatment. (A.b) MRI after 2 weeks of prednisolone. Arrows depict longitudinal hyperintense areas that ameliorate during immunomodulation. $\mathrm{T} 1+\mathrm{CE}=\mathrm{T} 1$-weighed image with contrast enhancement. (B) Cryosections of rat (B.a) or monkey cerebellum (B.b), murine whole brain (B.c), monkey exocrine pancreas (B.d), and recombinant HEK293 expressing the pancreatic autoantigen CUZD1 (B.e) were incubated with the patient's serum (1:100). Nuclei were counterstained by incubation with TO-PRO-3 iodide. Scale bar: $50 \mu \mathrm{m}$. 
(Borrelia, Treponema, Leptospira, Mycobacterium, Mycoplasma). CSF analysis displayed a slightly increased cell count $(5 / \mu \mathrm{L})$, elevated total protein (651 mg/L), a moderate impairment of blood-CSF barrier function (albumin-ratio $11 \times 10^{-3}$ ), and absence of oligoclonal bands or intrathecal immunoglobulin synthesis.

Indirect immunofluorescence assay (IFA) of the patient's serum displayed a strong granular cytoplasmic immunoglobulin $\mathrm{G}$ ( $\mathrm{IgG}$ ) staining in the molecular layer of rat, porcine, and monkey cerebellum at a titer of 1:1,000, but no staining of Purkinje cells, cell nuclei, or hippocampal neurons was observed (figure 1B). Testing with living or fixed rat hippocampal neurons was negative. Sagittal cryosections of murine whole brain demonstrated restriction of staining to the cerebellar molecular layer. CSF was not tested.

On the assumption of an autoimmune-mediated neurologic disorder, the patient received $250 \mathrm{mg} /$ day prednisolone. As a result, the patient's sensory loss dissolved within 1 week whereas tetraparesis improved much more slowly. Monitoring MRI confirmed regression of spinal cord lesions.

Identification of neuronal GluR 22 as the target autoantigen. Analysis of the IgG subclass distribution revealed IgG1 and $\operatorname{IgG} 3$ reactivities. Additionally, exocrine pancreas showed a reticulo-granular staining (figure $1 \mathrm{~B}$ ) that could be attributed to CUZD1 by recombinant cell IFA (RC-IFA). ${ }^{4}$ Further monospecific analyses were conducted with recombinant HEK293 cells expressing 28 established neural autoantigens: $\mathrm{Hu}, \mathrm{Yo}, \mathrm{Ri}$, CV2, SOX1, PNMA1, PNMA2, ARHGAP26, ZIC4, DNER/Tr, GAD65, GAD67, amphiphysin, recoverin, GABA B receptor, glycine receptor, DPPX, glutamate receptors (types NMDA, AMPA, mGluR1, mGluR5), LGI1, CASPR2, AQP4 (M1 and M23), MOG, MP-0, and MAG. However, none revealed specific reactivity.

Histoimmunoprecipitation with rat and porcine cerebellum and the index patient's serum revealed proteins with an apparent molecular mass of 110 $\mathrm{kDa}$ in sodium dodecyl sulfate polyacrylamide gel electrophoresis (SDS-PAGE) (figure 2). These proteins were absent in control histoimmunoprecipitates (HIPs). The precipitated protein could be identified

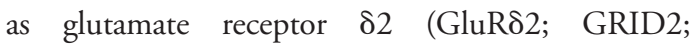
UNIPROT acc. Q63226) by matrix-assisted laser desorption/ionization-time of flight analysis. Western blot analysis of the HIP using a polyclonal anti-

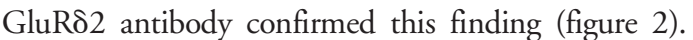
In contrast to anti-GluR $\delta 2$, the patient's autoantibody was not able to bind to the denatured $110 \mathrm{kDa}$ protein. When used in IFA, anti-GluR $\delta 2$ produced

Figure 2 Histoimmunoprecipitation and antigen identification

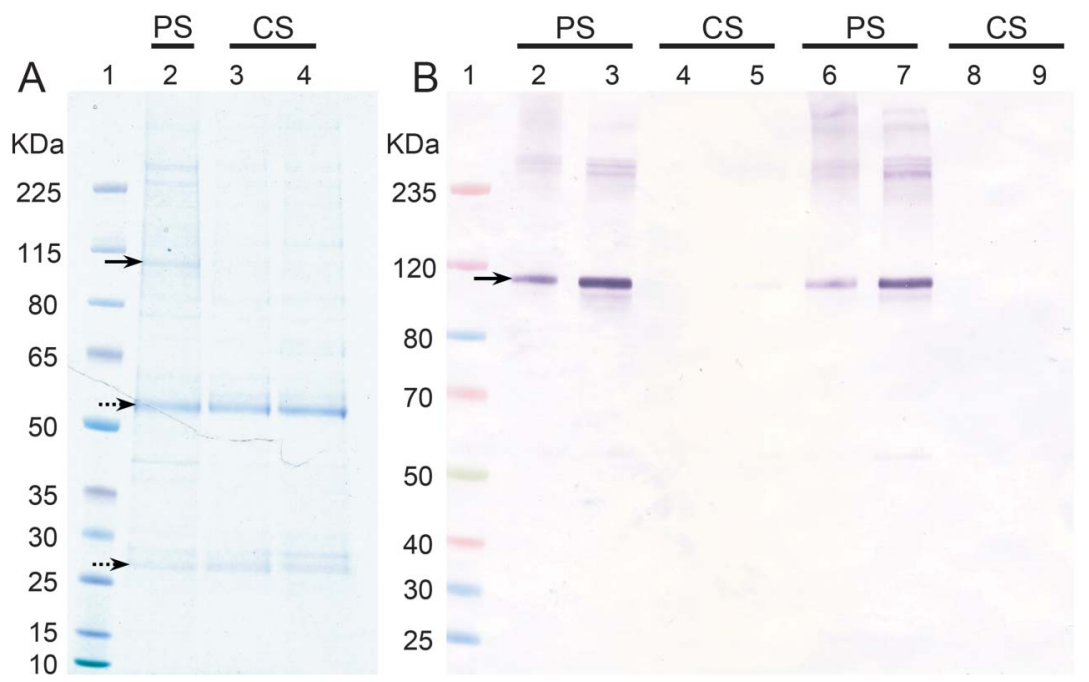

Cryosections of rat or pig cerebellum were incubated with the patient's serum (1:100), washed in phosphate-buffered saline, and solubilized using $1 \%$ Triton X-100. The solution was incubated with protein-G-coated magnetic beads. The immunocomplexes were eluted by sodium dodecyl sulfate (SDS) and subjected to SDS-polyacrylamide gel electrophoresis (PAGE) analysis and Western blot. (A) SDS-PAGE and staining with colloidal Coomassie. Lane 1: molecular weight marker. Lane 2: histoimmunoprecipitate of the patient serum (cerebellum rat). Arrows indicate the position of the immunoprecipitated antigen at $113 \mathrm{kDa}$ while dotted arrows indicate the position of immunoglobulin $\mathrm{G}$ heavy and light chain at $52 \mathrm{kDa}$ and $27 \mathrm{kDa}$, respectively. Lanes 3,4 : rat cerebellum precipitated with sera exhibiting as yet undefined neuroimmune reactions (controls). (B) Western blot analysis with polyclonal rabbit anti-GluR $\delta 2$ antibody. Lane 1: molecular weight marker; lanes 2, 3: histoimmunoprecipitate of the patient's serum (cerebellum rat); lanes 4, 5: rat cerebellum precipitated with sera exhibiting as yet undefined neuroimmune reactions (controls); lanes 6, 7: histoimmunoprecipitate of the patient's serum (cerebellum monkey); lanes 8, 9: monkey cerebellum precipitated with sera exhibiting as yet undefined neuroimmune reactions (controls). 
fluorescence patterns on rat and monkey cerebellum matching those generated by the patient's serum.

The patient's serum reacted in RC-IFA using live or fixed transfected HEK293 cells expressing GluR $\delta 2$ but not with mock-transfected cells (figure $3 \mathrm{~A})$. When used in neutralization experiments, HEK293 fractions containing GluR $\delta 2$ abolished the brain tissue reaction of the patient's autoantibodies (figure 3B). Antibody binding was unaffected when comparable fractions of mock-transfected cells or of cells expressing CUZD1 were used. Likewise, the autoantibodies against exocrine pancreas could be abolished by preincubation with CUZD1 but not

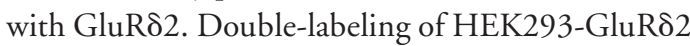
as well as of rat and monkey cerebellum with the patient's serum and the polyclonal anti-GluR $\delta 2$ antibody revealed a nearly perfect congruence (figure 3, C-E).

Disease specificity of anti-GluRס2 autoantibodies. Sera from 38 patients with early-stage relapsing-remitting multiple sclerosis of whom 19 presented with transverse myelitis and 85 with various neural autoantibodies (anti-NMDAR, anti-Hu, anti-Yo, antiRi, anti-AQP4, anti-LGI1, anti-CASPR2, anti-GAD) and 205 healthy participants were analyzed by IFA in parallel to the samples of the index patient. None of these control sera produced a similar immunofluorescence pattern on the different brain tissues or showed a reaction with the recombinant

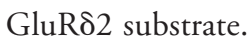

DISCUSSION We report high titer autoantibodies against GluR 2 in a patient who had received allogenic stem cell transplantation and developed graft vs host disease affecting the gut accompanied by transverse myelitis with tetraparesis, sensory loss below Th8, and incontinence. Much like formerly reported Japanese patients with anti-GluR $\delta 2$, our patient improved upon administration of steroids. The patient's serum reacted exclusively with the cerebellar molecular layer but not with hippocampal tissue and in vitro cultivated hippocampal neurons or with any of the 28 established brain autoantigens used in this study. GluR82 was histoimmunoprecipitated from cerebellum by the patient's IgG antibodies. The direct binding of the patient's antibodies to GluR $\delta 2$ was verified by RC-IFA using HEK293 cells expressing GluR $\delta 2$ and the neutralizing effect of
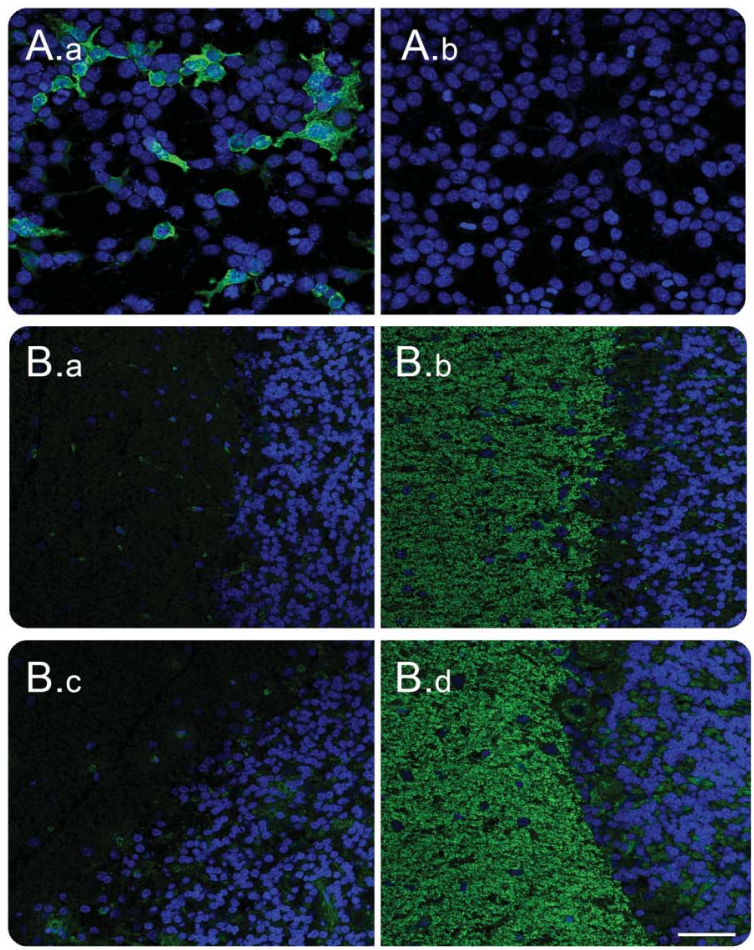
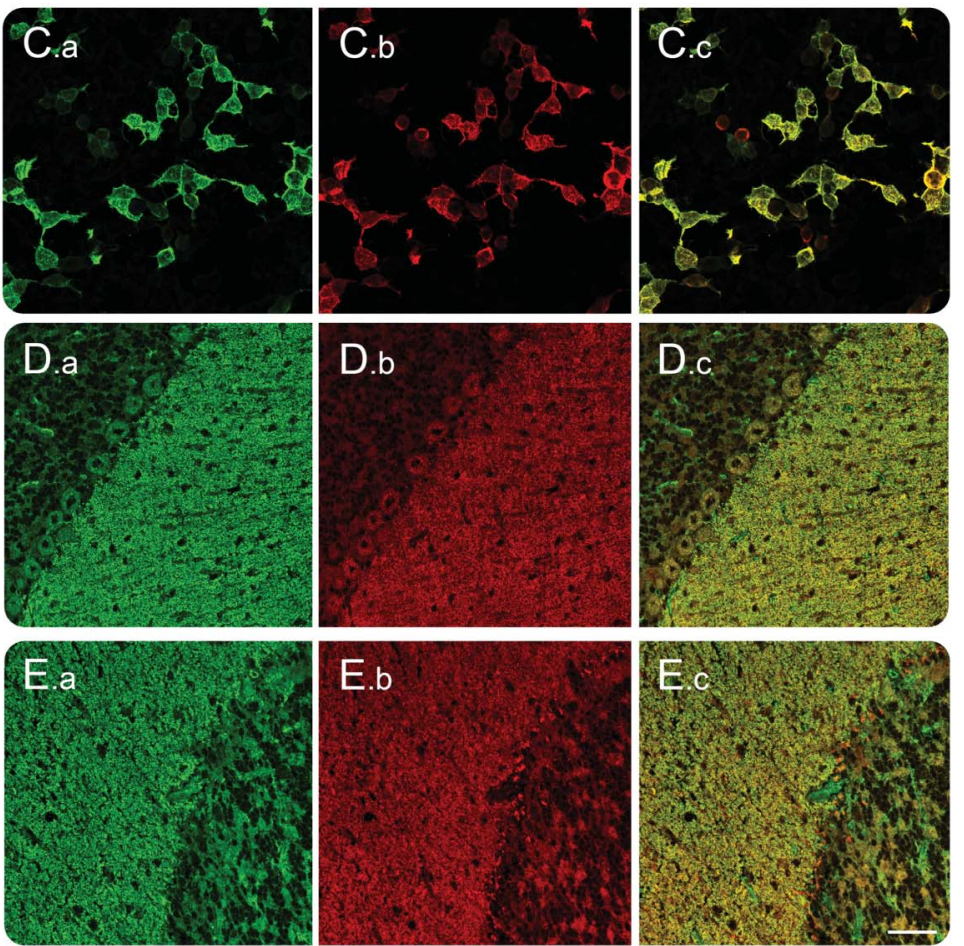

(A) Immunofluorescence analysis of transfected HEK293 cells. The patient's serum was incubated diluted 1:100 on formalin-fixed recombinant HEK293 cells expressing GluRd2 (A.a) or a mock-transfected control with empty vector (A.b). (B) Neutralization of immunofluorescence reaction on cerebellum (rat: B.a, B.b; monkey: B.c, B.d). The patient's serum diluted 1:320 was preincubated with extracts of HEK293 cells transfected with the GluRd2 (B.a, B.c) or with empty vector as control (B.b, B.d). The extract containing the GluRd2 abolished the immune reaction. Scale bar: $50 \mu \mathrm{m}$. (C-E) Immunofluorescence staining of recombinant HEK293 expressing GluRd2 (C.a-C.c), rat cerebellum (D.a-D.c), and monkey cerebellum (E.a-E.c). HEK293 and tissue sections with patient's serum diluted 1:100 (green, C.a-E.a) and 1:500 polyclonal rabbit anti-GluRd2 antibody (red, C.b-E.b). The merged images display colocalization of both reactivities (C.c-E.c). Scale bar: $50 \mu \mathrm{m}$. 
recombinant GluR $\delta 2$ on the autoantibodies' tissue binding. The experiments also demonstrate binding to an extracellular epitope because of the reaction with GluR 82 on the surface of live HEK293 cells.

Autoantibodies against GluR $\delta 2$ have so far only been described in a few Japanese patients with encephalitis. ${ }^{5-10}$ Neither the etiology nor the pathogenic roles of these autoantibodies have been clarified. However, the surface expression of GluR $\delta 2$ and the disease-ameliorating effect of steroids allow speculation about a direct pathogenic role of the autoantibodies as has been demonstrated for autoantibodies against NMDAR in autoimmune encephalitis. ${ }^{3}$ Our case supports this speculation by showing autoantibody binding to the extracellu-

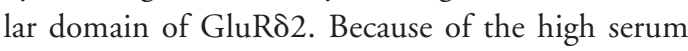
titer the presence in CSF is likely a result of the normal IgG diffusion through the blood-CSF barrier. We could, however, not investigate CSF to support this.

Anti-GluR $\delta 2$ should be considered in patients under suspicion of autoimmune encephalitis or myelitis in the absence of other autoantibodies even though it is very rare.

\section{AUTHOR CONTRIBUTIONS}

R.M. and S.H. were involved in immunoprecipitation, interpretation of data, antibody testing, microscopy, and writing of the manuscript. T.R., M.M., and C.T. were involved in the clinical definition of the patient. N.M. and H.M.M. was involved in the clinical definition of the control participants. Y.D. performed mass spectrometric analysis. S.B. and C.P. performed molecular biology work. I.M.D., S.M., and B.T. were involved in antibody testing and microscopy. W.S. and L.K. were involved in the conception and organization of the research project and in writing of the manuscript.

\section{ACKNOWLEDGMENT}

The authors thank Laura Grossmann, Susann Satow, Beatrice Schneider, Sabrina Voigt, and Beatrice Witt for technical assistance.

\section{STUDY FUNDING}

No targeted funding reported.

\section{DISCLOSURE}

R. Miske is employed by Euroimmun AG. S. Hahn is employed by Euroimmun AG. T. Rosenkranz served on the scientific advisory board for Biogen, Genzyme Sanofi, Roche, Teva, Merck, Bayer, and Novartis; and received travel funding and/or speaker honoraria from Novartis, Pfizer, Bayer, Merck, Teva, Genzyme, Sanofi, and Biogen. M. Muller and I.-M. Dettmann report no disclosures. S. Mindorf is employed by Euroimmun AG. Y. Denno is employed by Euroimmun AG. M. Scharf is employed by Euroimmun AG. S. Brakopp is employed by Euroimmun
AG. B. Teegen reports no disclosures. C. Probst is employed by Euroimmun. N. Melzer received travel funding and/or speaker honoraria from Biogen, GlaxoSmithKline, Teva, and Fresenius Medical Care; performs immunoadsorption about $5 \%$ of his time; and received research support from Fresenius Medical Care. H.-M. Meinck reports no disclosures. C. Terborg received speaker honoraria from Astra Zeneca and German Diabetes Society and received research support from Asklepios Proresearch. W. Stocker holds patents for Untersuchungen an unbeweglich gemachtem biologischem Material, Verfahren zum Nachweis von Anti-NMDA-Rezeptor-Autoantikörpern zum Einsatz in Diagnoseverfahren, and Diagnosekit sowie ein Verfahren zur Untersuchung einer menschlichen Patientenprobe auf das Vorhandensein von Neuromyelitis-optica-spezifischen Antikörpern; is employed by Euroimmun AG and Klinisch-immunologisches; and holds stock or stock options in Euroimmun AG. L. Komorwski is employed by Euroimmun AG. Go to Neurology.org/nn for full disclosure forms.

Received March 9, 2016. Accepted in final form May 11, 2016.

\section{REFERENCES}

1. Probst C, Saschenbrecker S, Stöcker W, Komorowski L. Anti-neuronal autoantibodies: current diagnostic challenges. Mult Scler Relat Disord 2014;3:304-320.

2. Leypoldt F, Armangue T, Dalmau J. Autoimmune encephalopathies. Ann NY Acad Sci 2015;1338:94-114.

3. Dalmau J, Gleichman AJ, Hughes EG, et al. AntiNMDA-receptor encephalitis: case series and analysis of the effects of antibodies. Lancet Neurol 2008;7:10911098 .

4. Komorowski L, Teegen B, Probst C, et al. Autoantibodies against exocrine pancreas in Crohn's disease are directed against two antigens: the glycoproteins CUZD1 and GP2. J Crohns Colitis 2012;7:780-790.

5. Matsumoto H, Okabe S, Hirakawa-Yamada M, et al. Steroid-responsive focal epilepsy with focal dystonia accompanied by glutamate receptor delta2 antibody. J Neuroimmunol 2012;249:101-104.

6. Shiihara T, Kato M, Konno A, Takahashi Y, Hayasaka K. Acute cerebellar ataxia and consecutive cerebellitis produced by glutamate receptor delta2 autoantibody. Brain Dev 2007;29:254-256.

7. Shimokaze T, Kato M, Yoshimura Y, Takahashi Y, Hayasaka K. A case of acute cerebellitis accompanied by autoantibodies against glutamate receptor delta2. Brain Dev 2007;29:224-226.

8. Kubota M, Takahashi Y. Steroid-responsive chronic cerebellitis with positive glutamate receptor delta 2 antibody. J Child Neurol 2008;23:228-230.

9. Ichikawa K, Kikuchi M, Takeshita S, Nezu A. A case of chronic recurrent cerebellar ataxia responding to steroid therapy. Brain Dev 2009;31:83-85.

10. Fukuoka T, Takeda H, Ohe Y, Deguchi I, Takahashi Y, Tanahashi N. Anti-glutamate receptor delta2 antibodypositive migrating focal encephalitis. Clin Neurol Neurosurg 2012;114:1351-1354. 


\section{Neurology \\ Neuroimmunology \& Neuroinflammation}

Autoantibodies against glutamate receptor $\delta 2$ after allogenic stem cell transplantation Ramona Miske, Stefanie Hahn, Thorsten Rosenkranz, et al.

Neurol Neuroimmunol Neuroinflamm 2016;3;

DOI 10.1212/NXI.0000000000000255

This information is current as of July 14, 2016

Updated Information \&

Services

Supplementary Material

References

Permissions \& Licensing

Reprints including high resolution figures, can be found at:

http://nn.neurology.org/content/3/4/e255.full.html

Supplementary material can be found at:

http://nn.neurology.org/content/suppl/2016/07/14/3.4.e255.DC1

This article cites 10 articles, 0 of which you can access for free at: http://nn.neurology.org/content/3/4/e255.full.html\#\#ref-list-1

Information about reproducing this article in parts (figures,tables) or in its entirety can be found online at:

http://nn.neurology.org/misc/about.xhtml\#permissions

Information about ordering reprints can be found online: http://nn.neurology.org/misc/addir.xhtml\#reprintsus

Neurol Neuroimmunol Neuroinflamm is an official journal of the American Academy of Neurology.

Published since April 2014, it is an open-access, online-only, continuous publication journal. Copyright $\odot$ 2016 American Academy of Neurology. All rights reserved. Online ISSN: 2332-7812.

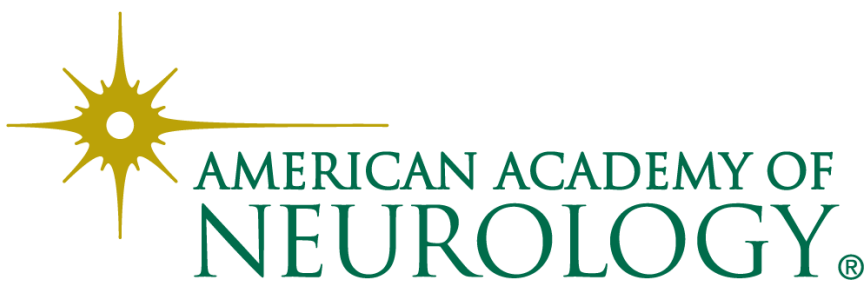

